\title{
MACROESTRUCTURACIÓN EN EL CUENTARIO LOS INFIERNOS DE LA MUJER Y ALGO MÁS DE RIMA DE VALLBONA
}

\section{Estébana Matarrita Universidad de Costa Rica}

El propósito del presente comentario es el de identificar dentro de un cuentario de catorce relatos de variados temas un factor cohesionante que permita intuir un sentido general global, que haga de la recopilación de esos textos una totalidad articulada por un propósito específico. Esta sería pues, la base de la hipótesis que propondremos para abordar el cuentario de la escritora costarricense Rima Rothe de Vallbona, titulado Los infiernos de la mujer y algo más.

Publicada en 1992, por Ediciones Torremozas de Madrid, esta obra de Vallbona continúa con un proyecto ideológico que se vislumbra desde su primer texto, Noche en vela, Premio Nacional de novela en Costa Rica en el año de 1968. Ya en esa primera obra, la vocación de Rima se inclina claramente hacia la denuncia de la opresión femenina, tiranía ejercida tanto por hombres como por las mismas mujeres, cómplices y esclavos al mismo tiempo de un sistema de representaciones mentales alienantes de la personalidad y mutiladores de la libertad necesaria para el desarrollo de una personalidad plena y libre de prejuicios. Le siguen a ella innumerables relatos, novelas y cuentos, en los que la misma preocupación aglutina el sentido semántico y estético de su escritura: la victimización de la mujer en una sociedad patriarcal dominada por el machismo y una sexualidad enfermiza que castra el sublime sentimiento del amor. La naturaleza femenina aparece constantemente, como la vocación por el afecto y la entrega generosa, como la cosmovisión metafísica de un mundo en el que sólo el amor y el sentimiento son capaces de llevar a la integración del yo con el universo y a la realización plena del ser con la totalidad de la creación. Las mujeres y los niños, son los personajes favoritos de Vallbona, porque ellos comparten de alguna manera su fe en el otro y en el afecto. Etapa infantil y vida adulta de la madurez, son los dos estadios de la vida de sus caracteres femeninos que son constantemente destacados, comparados, relacionados y permutados. No en vano, la tópica del paraíso es una de sus constantes metafóricas para representar, ya sea la inocencia de todo principio, como también la nostalgia del origen, el ansia de lo sagrado y la vuelta a la conciliación con lo absoluto. En el topos del paraíso se encuentra el paradigma de la puerta que marca un cambio de escenario, pero también un cambio de condición en la vida del hombre y de ahí la idea del deseo del retorno. Como lo señala María Amoretti en un artículo publicado en la Revista de Filología y Lingüística de la Universidad de Costa Rica, titulado "Rima de Vallbona: entre la permanencia y 
el exilio" (15 (2), 1989), en el cuentario Mujeres y agonías, de los trece relatos que lo conforman, sólo tres no se refieren a mujeres o niños. Mujeres y niños son el grupo mayoritario de los protagonistas de los relatos de Rima. Los niños son, en el caso del cuentario que nos ocupa, Los infiernos de la mujer y algo más, los grandes protagonistasausentes, cuando aparecen (y difícilmente aparecen) lo hacen como parte ineludible del contexto de la familia o del matrimonio. Sólo el cuento "El secreto mundo de la abuelita Anacleta" haría la excepción en este caso, ya se verá cómo.

Si recalco el hecho de estos grupos mayoritarios, es por la sencilla razón de que ellos, mujeres y niños, son las víctimas genéricas y generacionales de la sociedad patriarcal, ellos constituyen siempre el personaje que llena el papel de la figura arquetípica de la víctima propiciatoria, la perfecta permutación humana de la oveja en la pira sacrificial, por lo que comparten en la esfera semiósica de sus connotaciones: pureza e inocencia. Porque en el cuentario de Los infiernos de la mujer y algo más, de eso se trata, del juego entre la inocencia y la culpa, de la figura de la víctima que se inmola gratuitamente ( o tal vez no tan gratuitamente, como lo veremos).

Por el momento, regresemos al punto de partida. Decíamos al inicio, que nuestro propósito era el de indagar la posibilidad de la existencia de un factor cohesionante que permita asumir los diversos cuentos de ese cuentario como una totalidad, a pesar de la diversidad de temas, situaciones y personajes que los caracteriza, y a pesar de la diferencias que este cuentario pudiera presentar con otros de la misma autora, como lo acabamos de señalar en el caso de Mujeres y agonías (Vallbona, 1986).

Buscar ese eje articulatorio en un cuentario que se ve obligado a agregar en su título una especie de apéndice que advierte la heterogeneidad y heteroclidad de sus contenidos, pareciera una tarea bastante curiosa. Pero es justamente, ese "y algo más", lo que desde nuestro primer encuentro con el libro nos ha inquietado; por el sentido que parece advertir al lector, e inhibirlo, de que no intente encontrar en él una completa unidad, sino una parte que se sostiene a sí misma como un todo y luego otra que se agrega como el espacio de lo misceláneo y de lo inclasificado por inclasificable. Autor o editor, no lo sabemos, han actuado conforme a esa perspectiva y han organizado el conjunto en dos partes según ese criterio. Así, el cuentario que comentaremos consta de catorce relatos. Nueve se agrupan bajo la primera parte del título Los infiernos de la mujer y cinco en la segunda parte de él, $Y$ algo más. Este manejo mismo del título es ya una novedad en la práctica de la intitulación literaria, al punto de que da la impresión de que se están publicando dos libros en uno solo. El autor implícito nos ha organizado, entonces, de previo, cierto criterio de cohesión, porque efectivamente la llamada "Primera parte: Los infiernos de la mujer" contiene justamente relatos en los que sus protagonistas son todas mujeres. Mientras que en la llamada "Segunda parte: Y algo más" se reúnen los cuentos en los que los protagonistas no son mujeres, son todos hombres, a excepción de un extraterrestre.

Si hemos de hablar en términos bien precisos, buscar la cohesión sería, después de esta evidencia, cosa vana; pues la cohesión es una relación que se da en el nivel semántico, inaccesible ya por la diversidad real de temas, situaciones y personajes; mientras que la coherencia es otra cosa, es la totalidad que se encuentra en un nivel superior que desborda el contenido. Más allá de la cohesión, en un nivel semiótico, se encuentra la coherencia, que es la globalidad del sentido, el cual, efectuándose en los precisos mecanismos de producción de la significación, se 
ubica más bien en la forma, en ese tercer nivel helmsleviano que se denomina precisamente "significado mítico". La coherencia es entonces una especie de superestructuración que enlaza unidades menores. Van Dijk llama a éstas microestructuras y a aquellas macroestructuras. De ahí el título que le hemos dado a nuestro artículo, el cual creemos que recoge con mayor fidelidad epistemológica el objeto de nuestras preocupaciones textuales.

La experiencia sociocrítica de análisis de textos, compartida por un grupo de colegas, entre los que nos incluimos, adscritos todos al Instituto Internacional de Sociocrítica, con sede en Montpellier, Francia, nos ha hecho extremadamente sensibles a las macroestructuraciones paradigmáticas que gobiernan la producción textual, las cuales se nos revelan en cada análisis particular cada vez con mayor evidencia, hasta el punto de que hablamos más bien de códigos culturales. Este fenómeno nos ha permitido hacer algunos aportes a los estudios de identidad cultural y, de manera más general, a teorizar sobre ciertas categorías literarias entre las que podríamos citar la intertextualidad y la interdiscursividad como operaciones transculturales del sentido.

En relación con la identidad, en el caso concreto de la literatura hispanoamericana, muchos escritores, investigadores, críticos y pensadores en general, ya habían señalado el papel que desempeña el mito como mediación esencial en nuestra concepción de la realidad y, por ende, la importancia de su función en la interdiscursividad de la mayoría de nuestras producciones literarias. No obstante, frente a la categoría mítica autóctona, la presencia de los arquetipos judeo-cristianos tienen también una recurrencia casi obsesiva, siendo ellos también parte de nuestra cultura.

Tal es el caso de Cien años de soledad, obra considerada paradigmática en la formulación de nuestra identidad hispanoamericana.

En ese texto de Gabriel García Márquez comparten papeles estelares dos fuentes cosmogónicas y ambas parecen funcionar como interpretantes recíprocas: lo bíblico interpreta lo mítico aborigen y lo mítico aborigen interpreta lo bíblico.

Como ya lo afirmamos, en la obra de Rima de Vallbona también la tradición judeo-cristiana es una estructura de mediación, un filtro interpretativo de la realidad, pero está absolutamente ausente la categoría mítica autóctona-aborigen. En lugar de ella encontramos los esquemas de otra fuente mítica, la que deriva de la tradición clásica, lo cual no es por azar, ya que los esquemas judeo-cristianos se encuentran amalgamados históricamente con la tradición grecolatina, de la cual el cristianismo, sobre todo, es legítimo heredero, si no que lo digan Santo Tomás y Aristóteles, si no que se revise la Edad Media entera.

Si nos atenemos al concepto de interdiscursividad como un complejo de discurso con dominancia, en Los infiernos de la mujer y algo más, son los esquemas arquetípicos de la tradición judeo-cristiana los que conformarían en este caso la dominancia. Sin embargo, por un principio de estructuración inherente a la naturaleza misma de toda sustancia discursiva, el discuso judeo-cristiano lleva dentro de su seno la referencia misma a aquel otro discurso que lo antagonizó en el momento mismo de su emergencia, nos referimos especialmente a las formas discursivas de la mítica grecolatina y su relación con las formas discursivas del cristianismo en particular.

Esta sería la formulación de nuestra hipótesis: los códigos judeo-cristianos y la mitología clásica son las dos grandes macroestructuraciones del cuentario Los infiernos de la mujer y algo más, de cuya diálogica emerge, por lo demás, la víctima sacrificial como la figuración isótópica de la imagen de la mujer. 
Veámoslo no más en el primer relato del cuentario en cuestión: "La tejedora de palabras". El texto se abre justamente con una dedicatoria en la que se mencionan dos personajes de la literatura clásica; luego seguidamente aparece una cita de Homero como epígrafe que se refiere a Circe y sus palacios.

El cuento es de una extraordinaria cohesión interna, pues la Prof. Thompson, quien imparte un curso de Literatura Clásica, reencarna a la propia Circe y logra seducir y secuestrar a uno de sus jóvenes alumnos embrujándolo por medio de visiones en las que ella, en realidad una vieja sucia, fea y desgarbada, se aparece ante los ojos del joven Rodrigo en una atractiva y juvenil mujer de hermosa cabellera pelirroja. Al igual que Circe tejedora, la Prof. Thompson logra envolverlo en una tupida red de palabras por medio de las cartas que secretamente le envía para seducirlo. Cuando Rodrigo intenta escapar es ya demasiado tarde. No se le vuelve a ver y la Prof. Thompson continúa con su próxima víctima.

Circe, bruja, araña, sirena, la Prof. Thompson es el punto en el que se inserta una espesa red de discursos en el que la matriz es ineludiblemente Homero. Pero también, bruja, sirena, araña se reconstituyen en el contexto actual por la presencia de los felinos y el toque rojizo de una cabellera abundante que redistribuye los contenidos de discursos arcaicos en el moderno tópico también de la mujer fatal. Junto al Hades, el relato sutilmente incorpora las nociones de paraíso y de infierno, éste último con la valencia de la muerte. De modo que, con la dominancia de los esquemas míticos de la tradición grecolatina, en este cuento la tópica cristiana del paraíso y el infierno son funtivos que tan sólo ejercen la interpretancia de aquellos.

Pero cómo integrar este relato en el sentido general de la parte en la que ha sido clasificado, la parte de los infiernos femeninos? La relación es bien frágil, pero se da. Rodrigo asocia (sin fundamento, como dice él) a la vieja seductora con su madre, por el olor a soledad que ambas despiden. La madre de Rodrigo es víctima de la infidelidad de su marido quien la traiciona constantemente por amantes juveniles. La tejedora de palabras, la Prof. Thompson, es la hechicera que se propone como tarea liberar a Rodrigo de los principios pequeño-burgueses de su familia. En contraste con la clase de Homero, "el paraíso perfecto en donde sorbía embebido el frescor de alquel río de palabras que arrastraba consigo todos sus pesares y angustias..." (p. 14), está la realidad de Rodrigo: “...su realidad de fugaces amoríos, de conversaciones fútiles, de películas violentas y eróticas, del dolor de haber sorprendido las infidelidades de su imperial padre, de la sumisión dolorosa de su madrecita tierna, benévola, resignada..." (p. 14) A pesar de las diferencias que se pueden deducir entre estas dos imágenes femeninas : la de la madre de Rodrigo y la de la Prof. Thompson, a ambas las hermana "el penetrante olor a soledad" que ambas despiden.

En el relato "El secreto mundo de la abuelita Anacleta", una anciana tiraniza desde su cama barroca toda la familia con su vocerrón herrumbrado. Por travesura (y un poco por compensación), los nietos le regalan para su nonagenario aniversario dos bolos. Para sorpresa de todos, secretante la abuela se dedica a entrenar y se dispone a salir, después de muchos años de reclusión, nada menos que para ganar el Campeonato de Bolos. Lo llamativo de este cuento es la clandestinidad de la anciana, quien posee ese secreto mundo de donde saca su fuerza paulatinamente hasta maravillar con la potencia de la que es capaz el montoncito de huesos y pellejos que ella es. El mundo secreto de la abuela Anacleta es por inexplicable y clandestino confundido con lo diabólico, el infierno por metonimia, y es por ello sometida a un exorcismo. Esta 
práctica ritual de la tradición cristiana es un marcador de la presencia, de nuevo del discurso judeo-cristiano, reforzado por la figura de Job, la Samaritana, Baltazar y el demonio, como por la mención de las letanías, las Sagradas Escrituras y el Santo Grial. Este es el filtro dominante que mediatiza la construcción de un mundo familiar tiranizado por una ínfima mujer que esconde dentro de sí un infierno de energía, de la cual su hija es la víctima propiciatoria:

No lo podíamos creer. Dio un salto ágil del camón barroco y se vistió sin ayuda de nadie. Entonces pensamos al unísono que aquella mujercita de efímera apariencia, se había vivido torturándonos y esclavizándonos todo ese tiempo con el fin de conservarnos bajo su dominio. (p. 28)

El fingimiento de su debilidad, el encubrimiento de su verdad, es el secreto del mundo de la abuelita Anacleta. Entre las víctimas de sus abusos está su nieta, la narradora de escasos diez años. Teñido por la ingenuidad de la mirada infantil, el relato presenta a esta mujer tiránica, violenta y abusiva bajo el cálido tamiz con que una nietecita de diez años puede mirar a su abuelita, de ahí el inevitable diminutivo que contrasta con los superlativos del vozarrón, herrumbrado, despótico, tiránico, proyectil poderoso, ametralladora, etc. con que es descrita su presencia. Junto al código emotivo de la narración la resolución parece jocosa por el contraste, por la inverosímil imagen de una abuela nonagenaria campeona mundial de bolos.

En este texto, el discurso de la tradición grecolatina aparece tímidamente en una única recurrencia que menciona a Sísifo para describir la inútil rutina de Chelita, la criada. Lo que cuenta, para nuestros propósitos, además de la dominancia del discurso judeo-cristiano como mediación, es la confrontación con el abuso y la victimización aceptada, resignada, de los seres humanos que aceptan la tortura (el infierno), obligados por el lazo del afecto y el parentesco.

En "El corrector de la historia" dos almas solitarias establecen un diálogo mudo en el que cada uno ignora la reciprocidad del otro. El argumento se anuda en un error de interpretación idéntico para ambas partes y que resulta en el suicidio del hombre y el doloroso reconocimiento de la mujer de que su resolución de comunicarse finalmente con el vecino de soledades, ha llegado demasiado tarde para él y demasiado tarde para ella, quien a partir de la muerte de él, la vida suya será también mortuoria. El sentido del extraño título, "El corrector de la historia", se da justamente en el hecho de que ha habido un error de interpretación en ambos personajes y es el desenlace del cuento quien se erije en el corrector de su propia historia y en establecer la verdad de las correspondencias que se escaparon tanto a la mujer, desde cuya perspectiva se nos ofrece el texto mediante el estilo indirecto; como al hombre, de quien sabemos su modo de percibir la situación, gracias a la nota que le dirige a su vecina. Es decir, que hasta en el nivel de la narración hay una total correspondencia, pues el relato pudo haberse dado perfectamente desde la perspectiva del hombre y nada hubiera cambiado de su contenido, ni un sólo elemento de la historia, ni la ventana, ni el carro, ni el soliloquio-diálogo, ni el mundo de soledades y aspiraciones, nada hubiera cambiado, tal es la perfecta simetría de este cuento de la correspondencia perfecta. El cuento es entonces, desde el punto de vista estético, de una extraordinaria eficacia estructural, pues el paralelismo de esas vidas semantiza todos los niveles de la narración, hasta el punto en que se puede afirmar que lo que en él se ficcionaliza es la correlatividad misma. 
Queremos llamar la atención en el mundo de conceptualizaciones redundantes que se ofrecen para describir estas vidas paralelas: yerma, vacía, silencio, decrepitud, vejez, ausencia, ingratitud; y el significativo epígrafe que habla del afecto correspondido. El tema general es el absurdo y la fatalidad de que esos seres humanos dejan escapar, por miedo a un rechazo más, la única oportunidad de encontrar la reciprocidad en el afecto y la necesidad mutua. El relato se cierra con una directa referencia al título de la parte en la que ha sido clasificado:

No pudo más y prefirió de una vez por todas, acabar con el infierno asfixiante de la desolación sin remedio.(p.36)

Hay pues ya una definición de infierno: desolación sin remedio, es decir, eterna. En la palabra desolación se vienen a resumir entonces todas las conceptualizaciones redundantes: yerma, vacía, silencio, decrepitud, vejez, ausencia, ingratitud. Ese es el concepto de infierno que elabora el texto y nuevamente es un mundo secreto, como el de Anacleta, porque está oculto, porque no se deja ver, no se comunica y cuando aparece sorprende y asusta.

"El carro de la rutina" será el relato que termine de develar el sentido del infierno y del infierno específicamente femenino. En él, una puerta que se cierra abre paradójicamente el relato y este sentido de la paradoja es el que va a condensar el contenido del cuento en su desenlace. Pero la puerta, como ya lo habíamos mencionado al principio de este artículo cuando hablábamos de la tópica del paraíso, es también un marcador que separa dos contextos totalmente diferentes. Así, para la novia enamorada, detrás de la puerta quedan abandonadas y clausuradas para siempre sus ilusiones :

Con desaliento comprobó que hasta las promesas de paraíso-eternamente-mi amor-vida-mía , se habían transformado en nudos de víboras. Cuando alcanzó el poso de su virginidad desgarrada sin misericordia, al atardecer, llena de angustia, comprendió que había dado el paso definitivo e irreversible hacia el infierno. (p. 38)

Más acá de la puerta está, pues, para la mujer, el infierno del matrimonio.

El infierno es, según el sentido general del término, tormento o castigo. Es el lugar donde los condenados sufren castigo eterno, según ciertas religiones y muy particularmente la religión cristiana. Es, entonces, según la primera acepción una forma de vivir, una manera de calificar un estar en el mundo. Y según la otra definición, el infierno es un espacio, ese que demarca la puerta, en el relato en cuestión.

Por otra parte, el término infierno va siempre relacionado con la muerte, por contraste con la vida eterna, el infierno es la muerte eterna. Ya así lo había conceptualizado la tejedora de sueños en el primer relato del cuentario y por eso le ofrece a Rodrigo llevarlo al Paraíso, para salvarlo de la muerte.

El discurso es una formación que se constituye por una cierta regularidad que establece una relación entre las diferentes partes que lo componen, de modo que ninguna de ellas sabría subsistir desprendida del todo. Esa regularidad constitutiva puede verse también como un conjunto de reglas de articulación y transformación por las que los conceptos se amarran unos a otros en una peculiar complicidad o en una relación de antagonismo y repulsa. Es una especie de fuerza magnética que, por lo tanto, es capaz de atraer a signos de polos opuestos. 
Así, dentro del esquema mítico judeo-cristiano, el infierno es inconcebible fuera de su relación con la falta, con el pecado y el castigo. Por su parte, el arquetipo paradisíaco es un espacio marcado de armonía y símbolo de la felicidad. Pero paradójicamente también contiene al infierno, puesto que en él se origina la falta, el pecado original, el principio del pecado o el pecado de los principios del mundo. Es el lugar en que una caída se origina y, en consecuencia, pasamos del plano de lo alto al plano de lo bajo o subterráneo. Por eso el infierno es siempre un topos soterrado, colocado en el eje de lo bajo en todos los sentidos de este término. De ahí su equivalencia semántica con lo oscuro y con lo oculto.

La novia de "El carro de la rutina" se encuentra de repente en el espacio del infierno. Habría, entonces que preguntarse, bajo qué cargos, o pagando cuál falta.

Contigua a la noción de infierno está siempre la de la muerte, como ya lo explicamos, por eso a esta mujer no le queda otra salida que la del suicidio, pero el cuento nos prepara una salida contrastante.

La puerta se vuelve abrir bajo la llave del amo para darle paso a éste y, ante un nimio gesto de afecto, la protagonista olvida todo su contexto y situación, desaparecen sus pesares :

"Hola, querida, cómo has pasado hoy?, le preguntó, ella buscó en lo más generoso y sacrificado de su ser una sonrisa y dándole un beso en los labios, de maravilla, mi amor, de maravilla!, le respondió.” (p. 38)

La falta que hace de la mujer merecedora del infierno es su ilusa confianza en el amor, como afirmamos en el comentario al inicio de este relato y en la primera citación. La afirmación es genérica porque esta mujer representa, según el texto, a todas las demás:

Así, para siempre quedó unida con intrepidez en el caos rutinario y esclavista del matrimonio, como había visto a las demás mujeres, desde la abuela hasta la madre, pasando por hermanas y parientas y amigas y vecinas y desconocidas..., todas... las demás. Igual que todas ellas! .(p. 38)

Pero hay que prestar atención a los términos que describen el ser de esta mujer-colectividad: generosidad y sacrificio. Generosidad para dar aunque no reciba nada a cambio, la idea de reciprocidad o de ingratitud de la que hablaba "El corrector de la historia". El sacrificio, que la define como una víctima muy especial, la víctima propiciatoria, porque se inmola voluntaria y resignadamente.

"Los males venideros" cambia de forma abrupta las problemáticas de los anteriores relatos. Rita Creso, la protagonista, es una escritora cuya ficción termina por devorarla gracias a la voluntad de una computadora que cobra vida e independencia y transforma su última ficción en la historia del final de la vida de Rita Creso. El relato es ingenioso por el juego de cajas chinas en las que una ficción ficcionaliza a la ficción que la produce y se da tal confusión de realidades que, ya fuera del control de la escritora, ésta se ahovilla en el suelo para esperar inerte que su propia ficción la consuma. Rápidamente considerado, este cuento no se ubica en el criterio clasificador del autor implícito de Los infiernos de la mujer y algo más, pero he aquí que encontramos una vez más a una mujer en condición de inercia ante fuerzas que ella no controla y la avasallan. El monstruo del computador, el memorión mecanizado, como lo califica la instan- 
cia narradora, le usurpa su función de escritora, le roba su autonomía y termina tomando hasta la propia vida de Rita por su cuenta. La figura de la mujer escritora es imagen de la mujer liberada, ya lo dijo la abuela Anacleta:

Inútil empeño porque los hombres siempre nos arrebatarán ambos derechos para seguir como amos y señores nuestros!, era su repetida y desconsolada letanía. -Se han fijado que apenas si hay compositoras en el mundo de la música? Podríamos contarlas con los dedos de las manos. Se explica, se explica... La música se hace sentir por el sonido, mientras la pluma corre silenciosa por el papel de las escritoras quienes a escondiditas, y como si cometieran un pecado mortal, desafían al hombre con sus libros. (p. 26)

Las connotaciones de los nombres son presagios: Mr. Congos, representante de la TWD ("tedoblevede") Business Systems. Pareciera ser pues, en la historia de Rita Creso, el castigo velado por su atrevimiento y desafío de mujer escritora. Por eso ella es también víctima del mismo esquema del vasallaje, representado en el monstruo todopoderoso del computador, cuya portentosa memoria escribe la historia de "Los males venideros"; y representado también en la proxémica del gesto del cuerpo que se ahovilla (posición fetal de la indefensión y del desamparo) en el propio suelo, posición que recuerda también a la víctima sacrificial por antonomasia, la oveja en la pira inmolatoria, que espera, indefensa, el golpe que le ha de quitar la vida. Así, Rita se dice para sí misma:

Ella sabe que de nada le servirá correr a esconderse, gritar, pedir auxilio a los vecinos, telefonear a la policía. Todo sería en vano. No vale la pena hacer ningún esfuerzo. (p. 46)

Pero es que, además, a pesar de la vida liberada de esta mujer profesional, hay una fraternidad de relaciones con las anteriores protagonistas: la condición de la soledad, el abandono de los hijos. Por eso, el oficio de escribir es para Rita Creso el escape de su infierno:

A qué temer? Sólo a mi sola soledad de vieja solitaria inmersa en soliloquios y fantaseos... (p. 42)

La imagen de la víctima propiciatoria vuelve a ser el encuadre en que aparece la figura femenina en "Brigada de la paz", relato en el que una multitud de mujeres es inmolada en los campos de batalla. El miedo y la incomunicación hacen que los combatientes, en la oscuridad de la noche, no se enteren de que el himno de guerra y de triunfo que canta el ejército enemigo avanzando hacia sus trincheras, no es más que el cántico de paz y amor que entona la brigada de la paz, "constituida por mujeres voluntarias -madres, hermanas, esposas, novias, estudiantes, obreras, que visitan el teatro de la guerra cantando el himno "Paz y amor en el mundo". (p. 50)

Ante el espectáculo de la muchedumbre de cadáveres, los soldados exclaman:

“-Mujeres! Sólo son mujeres! Indefensas mujeres sin más armas que un canto de paz y amor!" (p. 50) 
Otra vez la figura femenina en estado de indefensa postración, entregada a la muerte, en busca del amor. Víctima inocente.

El desenlace del cuento es inesperado porque la visualización de los hechos está dada desde la perspectiva masculina de los combatientes, quienes ni siquiera serían capaces, dado el escenario de la guerra y el miedo que los invade, de hacerse la pregunta que la cita (en inglés) de Gibran plantea en el epígrafe y que se puede resumir de la siguiente manera: "Puede alguien que ama encontrar e intercambiar besos en los campos de batalla todavía acres por la fumareda de las bombas?"(p. 47)

El relato es, entonces una respuesta implícita, que no necesita ulteriores comentarios.

Otra respuesta ofrece el texto titulado explícita y significativamente "El infierno", pero esta vez es una respuesta a una pregunta que nos habíamos formulado en relación con el sentido del infierno y la falta que justifica el castigo de estar en él.

Un epígrafe que define la irracionalidad como categoría diabólica explicaría el cómo es tan fácil pasar de la semántica del cielo a la del infierno. O, podríamos pensar más bien que es el argumento de este cuento el que le da sentido a las enigmáticas observaciones de esa cita de Milán Kundera. Se trata también de una mujer atada al "carro de la rutina", quien decide un día romperla y al hacerlo "todo su ser se le volvió cielo". Se lanza por los caminos de la libertad en busca del amor entregándolo a su paso por raudales. Pero a cambio de ello, termina prostituida y con un puñado de billetes en sus manos.

Decepcionada, intenta regresar a su antiguo mundo pero ya los caminos le están vedados:

Todo su esfuerzo fue en vano: el sueño donde había penetrado por los caminos de la libertad cerró las rejas y la dejó aprisionada para siempre en el allá y el antes, que habiendo sido cielo por unos momentos, se le volvieron infierno... (p. 53)

Entre los ámbitos del paraíso y el infierno aparece de nuevo el marcador de la puerta, representado en este caso por las rejas. En una semiótica de metáforas, este relato vuelve a presentar a la figura femenina castigada por el amor.

En seguida, su amor y sus besos, los fue dando a uno, a otro, a otros más y a cambio, ellos le devolvieron lágrimas y desilusiones; desilusiones y lágrimas. (p. 52)

El sueño y la ilusión truncados por la ingratitud. Otra vez emergen el sentimiento del desamparo y la soledad, el cansancio y la vejez.

Estos mismos semas definen la vida de la protagonista del siguiente cuento, "Una estrella fugaz", en el que una viejecita asediada por los achaques de la ancianidad y el vacío del final de su vida solitaria, se aferra también a una ilusión efímera, la emoción de ver una estrella tan espléndida "como la primera del Génesis". Al final, doña Amparo constata que su estrella nunca fue estrella, que la esperanza a la que aferraba los últimos girones de su vivir, era tan solo el inmenso, intenso foco de un avión. Ante el vacío del abandono, de la carencia de afectos, la vida es un espejismo en el que la muerte "tarda una eternidad en llegar".

"Libelo de repudio" es el último de los cuentos de Los infiernos de la mujer y con él se consuma la conceptualización de la mujer como víctima. 
El epígrafe es, como en otros casos, una cita bíblica (Deuteronomio). Como el título lo señala, en este relato la mujer sufre el repudio de su marido después de haberle entregado a éste lo mejor de su vida:

Ahora que tenés la farmacia y podemos vivir holgadamente, comprarnos una casita, la que tanto soñé para Marquitos, ahora jue'puta, que ya no necesitás de esta imbécil babieca, me venís con que "lo siento Ana, Anitica de mi vida, pero no puedo seguir con vos, porque sabés?, me he enamorado de otra y a vos no te puedo engañar. (p. 60)

El engaño es la figura clave, pero más que el engaño del marido, se trata del engaño de sí misma, como el de la novia de "El carro de la rutina": el engaño de entregar la fe en el amor. Como en otros relatos, la caída de la mujer reside precisamente en entregarse al amor sin condiciones.

La rutina de esta pareja es la diaria discusión nocturna por el divorcio, hasta que una noche el marido inusualmente acepta que la esposa se lo niegue. Las dudas de Ana ante esta inesperada reacción de su marido y la subrepticia sonrisa que ella cree ver en él en el momento en que éste se voltea para entregarse al sueño, desatan en la protagonista las dudas de que la haya envenenado. Entre los efectos de los somníferos y esa duda, Ana entra en un sopor que ni ella ni el lector pueden distinguir si es el sopor de las drogas o el de la muerte:

Mientras se va hundiendo en la inquietante negrura, "se pregunta cómo puede el asesino dormir y roncar tranquilamente al lado de su propia víctima. Estará soñándolo? Y si todo fuera sólo una pesadilla y mañana...? Mañana?... Y si ma...ña...na...des...pe...r...t...a...r..aaa? (p. 63)

Ana se autodefine como víctima, pero víctima inocente como la sacrificial. Por eso la noción de falta sufre en este relato, como en varios otros a los que nos hemos referido, una reinversión, pues el agente de la falta es la propia víctima. La caída que hace a la mujer merecedora de su muerte o de su infierno es su actitud ilusa ante el sentimiento del amor. Por eso, en este cuento la revelación consiste en enterarse de que por ilusa Ana ha sido víctima de un timo, que se hace evidente en el juego de palabras entre timo y Timoteo, el nombre de su marido.

Pero la víctima inocente está hecha para la inmolación, su existencia se define sólo en función del holocausto (entre los judíos: sacrificio religioso en el que la víctima era quemada, fuego, infierno); por eso, en "Brigada de la paz", la muchedumbre de mujeres se describe como "la última esperanza de que la raza humana no sea eliminada del planeta" (p. 50), y su muerte representa también la figura del holocausto, del sacrificio, porque holocausto tiene también una segunda acepción: gran matanza.

El mito de Sísifo, tan redundante en estos relatos en la idea de la cotidianidad, de los gestos inútiles de entrega, de la ilusión que, aunque fantasmagórica, no deja de construirse repetidamente, asienta en esta sección del libro la idea del destino, otro sema isotópico, de la mujer como figura crística del sacrificio, pues la inmolación a la que está destinada es una inmolación por el amor y por la paz, la armonía de su vida y la de los suyos; y frente a este destino no hay rebeldía posible, de ahí la aceptación. Su inmolación es la condena de soportar el infierno de la ingratitud, del desamor y el abandono como pago a su entrega. 
En la sección " $Y$ algo más" los motivos de la primera parte se reiteran, a pesar del carácter misceláneo de los cuentos: las luchas fratricidas, el fin del mundo, el rico y la pobreza, la reencarnación, el tiempo que se esfuma, etc. Se sigue, a pesar de esta variedad, el mismo mecanismo de macroestructuración de la primera parte del cuentario, al menos en lo que se refiere a las mediaciones de la escritura.

El cuento "Cruzada Intergaláctica" tiene como epígrafe una cita del apocalipsis de San Juan que resulta muy reveladora, puesto que el Inspector General del Imperio Intergaláctico, luego de hacer un escrutinio de los despojos de este planeta, que lo lleva a la conclusión de que debe ser destruido para evitar la vergüenza y la contaminación de la estulticia en la Galaxia, agrega en una post data, al final de su informe, la recomendación de considerar el rescate de lo único valedero dentro del vergonzoso desecho: las enseñanazas de Jesús, el Redentor.

Los conceptos de la vida como expiación, como valle de lágrimas y la presencia del infierno y de la muerte aquí en la tierra, por ejemplo, siguen siendo reinterpretantes de los arquetipos judeo-cristianos.

En el cuento "Una vez más Caín y Abel", se retoma la problemáticaá de las luchas fratricidas. El relato se contextualiza en Nicaragua, durante los combates entre la resistencia y los sandinistas. El epígrafe contiene una cita también del Génesis para cerrar luego el mensaje con una consigna muy sorprendente que intenta acabar con esa esencial polémica. En medio de los preparativos del combate, los soldados se susurran esa consigna y ante la sorpresa de los jefes de ambos bandos, en el momento del enfrentamiento y al grito de la consigna:

Todos, todos los de un bando y de otro bando, dejan el mundo perplejo cuando en un abrazo apretado y fraternal gritan con un grito ubicuo que siguen repitiendo hasta la saciedad: -Hermanos, somos hermanos. A partir de hoy. Caín y Abel unidos para siempre. (p. 85)

Una situación actual es reinterpretada a través de esquemas ancestrales provenientes de la tradición judeo-cristiana, al igual que en el siguiente cuento, Justicia distributiva". Allí, a partir de otras citas bíblicas (San Lucas y San Mateo) se aborda el tema del rico y se cuestiona la posibilidad de que éste con su dinero pueda comprar la salvación eterna a pesar de sus gestos de caridad. Se trata de una reflexión sobre el sentido de la caridad en los tiempos modernos. Culpa, pecado, salvación eterna, son la nociones claves:

El pecado más gordo no es el de los que se embolsan dinero que les pertenece a otros, ni el de los que despojan a los pobres. El pecado más gordo es el de aquel que pensando sólo en su ego, sin preocuparse por los otros, se encarama a toda costa (o pretende encaramarse) en el reino de los cielos. (p. 92)

En fin, todos los temas de esta sección última del libro, de ese $Y$ algo más, tienen en común el hecho de ser redistribuciones de los esquemas bíblicos que remodelan también los cuentos de Los infiernos de la mujer.

Hay, pues, en el libro, un nivel de coherencia que desborda las temáticas por ser una articulación que se da en las categorías interpretantes del mundo puestas al servicio de una intención autorial (consciente una veces, intuida o no consciente, las más) que atraviesa cada uno de los re- 
latos de este cuentario para poner en escena, una vez más, en otra de sus obras, los códigos culturales que gobiernan la sociedad y la época en la que estas producciones culturales aparecen.

Rima de Vallbona es, en este sentido, como todo buen escritor, un fino oído que sintoniza las preocupaciones y aspiraciones de sus coetáneos, pero sobre todo las de sus hermanas de género, para desplegar un horizonte de mayor visibilidad social que nos permita mirar también con mayor lucidez en el fondo del paraíso o el infierno de nuestras conciencias.

\section{Bibliografía}

Amoretti Hurtado, María. 1989. "Rima de Vallbona: entre la permanencia y el exilio". Revista de Filología y Lingüística de la Universidad de Costa Rica. 15 (2): 23-27.

Vallbona de, Rima .1986. Mujeres y agonías. Houston: Arte Público Press. . Los infiernos de la mujer y algo más. Madrid: Torremozas. 1992. 